\title{
PENINGKATAN KUALITAS AIR SUNGAI UNTUK IRIGASI PERSAWAHAN PADI DENGAN SISTEM “KONTROL PH” DI KABUPATEN BENGKALIS, RIAU
}

\author{
Oleh : Ir. Setiyono, M.Si dan Ir. Sri Rahayu, M.T. \\ Pusat Teknologi Lingkungan, BPPT
}

\begin{abstract}
Bengkalis district has a population of 690,366 people spread in the area of 11,481.77 $\mathrm{Km}^{2}$. Natural resources potencial in this area is quite large, so that local Government has a high commitment to meet the demand of local food, and even regional. To implement this goal, local government will build irrigation systems to irrigate 1,500 ha of rice field land which decrease of water in dry season. However, there are some constraints experienced are : the river for irrigation water source is located near the beach, so it is influenced by tidal sea water. Besides, the peat moss water contains a high organic matter and acid. To solve this problem, we need to treat the river water for irrigation, so that its quality meets the requirement for agriculture. While tidal conditions can be set with the pumping time. From the results of the research in the laboratory showed that the river water $\mathrm{pH}=4$ while the river water quality standard for the rice field is the appropriate 5 - 9 $\mathrm{mg} / \mathrm{l}$. Therefore, the required water treatment to raise $\mathrm{pH}$ to comply with the standard quality of water for agriculture. Research conducted in the village Langkat, district Siak Kecil. This activity includes laboratory research, design creation tool to increase $\mathrm{pH}$ river water irrigation, tools development, up to the trials and monitoring.
\end{abstract}

Keywords : Peningkatan Kualitas Air, Irigasi Persawahan, Kontrol pH

\section{PENDAHULUAN}

\subsection{Latar Belakang}

Beras merupakan komoditi andalan yang sangat penting untuk mendukung ketahanan pangan suatu wilayah. Luasnya lahan persawahan merupakan potensi yang dapat mendukung tersedianya pangan guna mencukupi kebutuhan lokal maupun regional. Keseriusan dan komitmen Pemda Kabupaten Bengkalis dalam membangun ketahanan pangan diwujudkan dengan telah dibangunnya proses pengolahan beras yang modern dengan kapasitas 6 ton/jam dan rencana membangun sistem irigasi guna mengairi 1500 ha lahan persawahan yang kekurangan air ketika musim kemarau.

Pembangunan sistem irigasi dengan air sungai mempunyai kendala antara lain, wilayah yang dekat pantai menyebabkan sungai dipengaruhi oleh pasang surut air laut dan airnya bergambut (kadar organik tinggi dan bersifat masam). Pasang surut dapat dihindari dengan mengatur waktu pemompaan, sedangkan kemasaman air memerlukan perlakuan sebelum digunakan untuk keperluan pertanian.

\subsection{Tujuan dan Sasaran}

Tujuan dilakukannya kegiatan ini adalah untuk mendapatkan sistem pengolahan air gambut yang mudah diaplikasikan guna memenuhi kebutuhan air irigasi pertanian tanaman padi. Adapun sasaran kegiatan ini adalah membangun satu unit percontohan alat pengolah air gambut untuk keperluan irigasi pertanian.

\subsection{Ruang Lingkup}

Ruang lingkup yang akan dilaksanakan dalam kegiatan ini adalah :

1. Survai lokasi intake yang sesuai untuk lokasi lahan uji coba serta mencari pengaruh pasang surut terhadap tinggi muka air sungai.

2. Menentukan sistem peningkatan kualitas air dan disain teknisnya.

3. Membangun unit percontohan pengolahan air gambut untuk pertanian.

\section{METODOLOGI}

\subsection{Survai Lapangan}

Survai kegiatan ini dilaksanakan di wilayah Kabupaten Bengkalis dengan melakukan observasi lapangan untuk meninjau langsung lokasi pertanian padi serta sumber air yang akan diolah dan pendataan petani padi.

\subsection{Tinjauan Pustaka}

\subsubsection{Proses Netralisasi}


$\mathrm{pH}$ air secara alami berkisar antara 4 sampai 9, dan secara teoristis $\mathrm{pH}$ dari 0 sampai 14. $\mathrm{pH}=0$ disebut air bersifat sangat asam dan $\mathrm{pH}=14$ disebut bersifat sangat basa, sedangkan $\mathrm{pH}=7$ menunjukkan air yang netral pada suhu $25{ }^{\circ} \mathrm{C}$. Netralisasi adalah merupakan suatu upaya agar $\mathrm{pH}$ air itu normal. Ketidak normalan $\mathrm{pH}$ air ini disebabkan oleh pemasukan atau penambahan asam atau basa. Netralisasi dalam pengolahan air gambut adalah suatu upaya untuk mengatur $\mathrm{pH}$ air baku yang bersifat asam $(\mathrm{pH}<$ 7) menjadi mendekati netral/normal $(\mathrm{pH} 7$ - 8), dengan cara pembubuhan alkali. Cara yang paling mudah dan murah yaitu dengan membubuhkan $\mathrm{CaO}$ (kapur tohor) atau $\mathrm{CaCO}_{3}$ (batu gamping).

\subsubsection{Proses Peningkatan Kualitas Air Yang Diterapkan}

Secara umum ada dua parameter untuk menilai kesesuaian kualitas air untuk kebutuhan pertanian, yaitu nilai SAR dan salinitas. Nilai SAR dapat dihitung dengan menggunakan persamaan sebagai berikut ${ }^{4)}$ :

SAR

$$
=\frac{\mathrm{Na}^{+}}{\sqrt{\left(\mathrm{Ca}^{2+}+\mathrm{Mg}^{2+}\right) / 2}} .
$$

Tanah dengan kandungan $\mathrm{Ca}^{2+}$ dan $\mathrm{Mg}^{2+}$ yang tinggi akan mempunyai sifat fisik yang baik untuk pertumbuhan tanaman. Jika tanah yang mengandung ion $\mathrm{Ca}^{2+}$ dan $\mathrm{Mg}^{2+}$ yang tinggi ini diairi dengan air yang mengandung ion $\mathrm{Na}^{+}$tinggi, maka akan terjadi pertukaran ion $\mathrm{Na}^{+}$ dengan ion $\mathrm{Ca}^{2+}$ dan $\mathrm{Mg}^{2+}$ di dalam tanah. Jika pengairan dengan menggunakan air dengan kandungan ion $\mathrm{Na}^{+}$tinggi dilakukan dalam jangka panjang akan mengubah sifat fisik tanah, menjadi impermeabel (tidak lulus air) sehingga tidak baik untuk pertumbuhan tanaman ${ }^{5}$.

Menurut US Salinity Laboratory tanaman dapat dikelompokkan menjadi sensitif terhadap salinitas, moderat dan toleran. Tanaman buahbuahan dan kacang-kacangan termasuk yang sensitif terhadap salinitas. Laboratorium Salinitas Amerika Serikat mengembangkan model grafik untuk mengevaluasi hasil analisis kimia air untuk kepentingan pertanian ditinjau dari parameter SAR dan salinitas. Gambar 1 menunjukkan grafik pengelompokkan air berdasarkan nilai SAR dan salinitas.

Dengan menggunakan grafik tersebut di atas, maka kualitas air dapat dikelompokkan menjadi tiga ${ }^{4)}$ :

1. Kelompok air dengan resiko sangat tinggi jika dipergunakan sebagai air irigasi pertanian (area S3). Sebaiknya air ini tidak digunakan untuk keperluan pertanian.

2. Kelompok air dengan resiko tinggi dari aspek DHL tetapi tergolong beresiko medium dilihat dari nilai SAR (area S2) jika dipergunakan sebagai air irigasi pertanian, sehingga disarankan tidak digunakan untuk keperluan pertanian.

3. Kelompok air dengan resiko rendah dilihat dari nilai SAR tetapi sedang sampai tinggi dari nilai salinitas (area S1), sehingga masih memungkinkan untuk dipakai sebagai air pertanian.

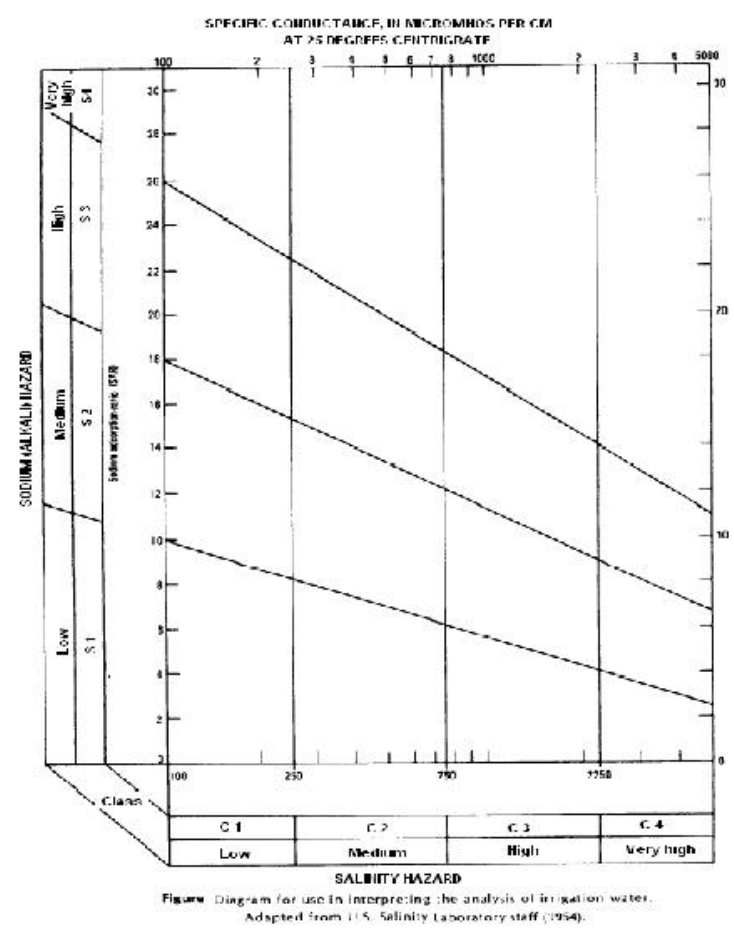

Gambar 1. Pengelompokkan Air Berdasarkan Nilai SAR Dan Salinitas (Model US Salinity Laboratory) ${ }^{4)}$.

\subsubsection{Pemeriksaan air di lapangan dan Analisis Laboratorium}

Untuk tahap awal dilakukan uji penelitian langsung di lapangan, yang menyangkut analisa kualitas air sungai dan uji pengolahan air secara langsung. Analisa dilakukan secara sederhana dengan pengukuran $\mathrm{pH}$ dan derajat kadar garam. Sedangan uji pengolahan dilakukan dengan cara pengaturan $\mathrm{pH}$ air secara sederhana dan uji pengendapan air secara langsung maupun dengan bantuan bahan kimia koagulan dan flokulan.

Selanjutnya dilakukan Analisa laboratorium untuk mengetahui kualitas air sungai yang akan digunakan sebagai sumber air irigasi dan analisa kualitas tanah pada lokasi 
yang direncanakan untuk penanaman padi. Analisa kualitas tanah juga dilakukan untuk melihat karakteristik tanah pertanian setempat dan untuk melihat kebutuhan unsur hara bagi pertanian padi. Analisa laboratorium dilakukan di laboratorium yang ada di Jakarta dan sekitarnya.

\section{PELAKSANAAN KEGIATAN}

\subsection{Gambaran Umum Wilayah}

Bengkalis merupakan salah satu Kabupaten di Propinsi Riau. Wilayahnya mencakup daratan bagian timur pulau Sumatera dan wilayah kepulauan, dengan luas adalah $11.481,77 \mathrm{Km}^{2}$, dan mempunyai batas-batas sebagai berikut ${ }^{3)}$ :

- Sebelah Utara berbatas dengan Selat Malaka

- Sebelah Selatan berbatas dengan Kabupaten Siak

- Sebelah Barat dengan Kota Dumai, Kabupaten Rokan Hilir dan Kabupaten Rokan Hulu

- Sebelah Timur dengan Kabupaten Karimun dan Kabupaten Pelalawan

Kabupaten Bengkalis beriklim tropis yang sangat dipengaruhi oleh sifat iklim laut, dengan temperatur berkisar $26^{\circ} \mathrm{C}-32^{\circ} \mathrm{C}$. Musim hujan biasa terjadi antara bulan September hingga Januari, dengan curah hujan rata-rata berkisar antara antara 809-4.078 mm/tahun Periode kering (musim kemarau) biasanya terjadi antara bulan Pebruari hingga Agustus. Di samping letaknya yang strategis Kabupaten Bengkalis juga menyimpan sumberdaya alam yang cukup besar bahkan kekayaan alam bumi Bengkalis, baik sektor migas seperti minyak bumi yang terdapat di Kecamatan Mandau dan Kecamatan Merbau maupun non migas, seperti hasil perkebunan, hasil perikanan dan lain-lainnya.

Secara Administrasi Pemerintah Kabupaten Bengkalis terdiri dari 13 (tigabelas) wilayah Kecamatan, yaitu :

- Kecamatan Bengkalis ( luas $514,00 \mathrm{~km} 2$ ),

- Kecamatan Bantan ( luas 424,40 km2),

- Kecamatan Bukit Batu (1.128,00 km2),

- Kecamatan Mandau (luas 937,47 km2),

- Kecamatan Merbau ( luas 1.348,91 km2),

- Kecamatan Rupat (luas 1.524,85 Km2),

- Kecamatan Tebing Tinggi (luas 1.436,83 $\mathrm{km} 2$ ),

- Kecamatan Rangsang (luas 922,10 km2),

- Kecamatan Rangsang Barat (luas 241,60 $\mathrm{km} 2$ ),

- Kecamatan Rupat Utara $(628,50)$ dan

- Kecamatan Tebing Tinggi Barat (luas 586,83 $\mathrm{km} 2$ ),

- Kecamatan Pinggir (luas 2.503,00), Kecamatan Siak Kecil (luas 742,21 km2) ${ }^{3)}$.

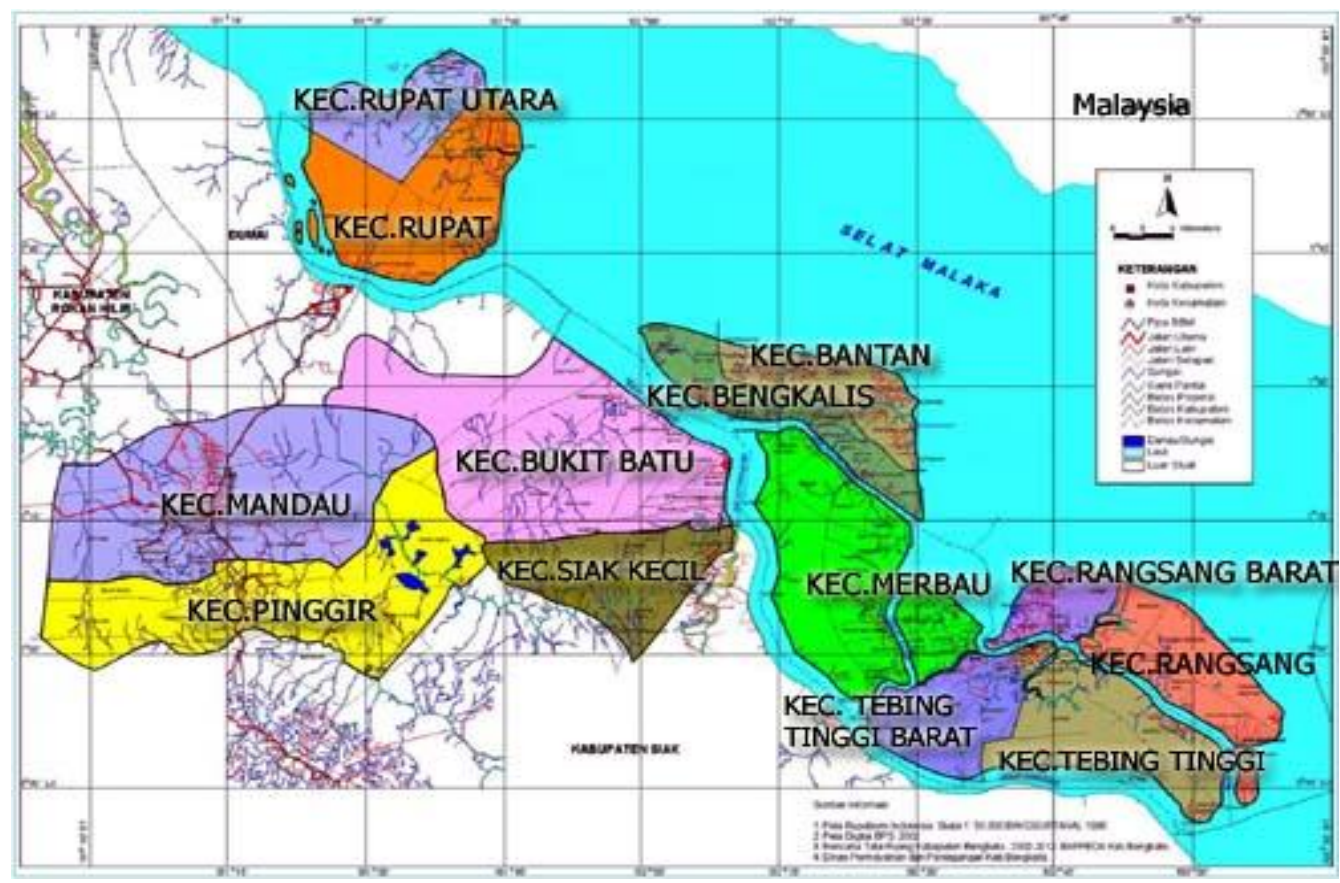

Gambar 2. Peta Kabupaten Bengkalis ${ }^{3)}$ 
Di dalam 13 Kecamatan tersebut terdapat 24 Kelurahan, 155 Desa dengan luas wilayah 11.481,77 $\mathrm{Km}^{2}$. Tercatat jumlah penduduk Kabupaten Bengkalis 690.366 jiwa dengan sifatnya yang heterogen. Mayoritas penganut agama Islam, disamping Suku Melayu yang merupakan mayoritas juga terdapat sukusuku lainnya seperti : Suku Minang, Suku Jawa, Suku Bugis, Suku Batak, Tionghoa dan sebagainya ${ }^{3)}$.

Lokasi Penelitian yang direncanakan adalah di Kecamatan Siak Kecil, yang mempunyai data administrasi sebagai berikut ${ }^{3)}$ :

- Kota Kecamatan : Lubuk Muda.

- Luas : 742,21 $\mathrm{Km}^{2}$

- Penduduk : 22.377

- Kelurahan : Sepotong.

- Desa : Langkat

- Suhu Max/Min : $33^{\circ} \mathrm{C} / 28^{\circ} \mathrm{C}$.

- Sebelah Utara berbatasan dengan Kec.Bukit Batu, Kec. Bengkalis.

- Sebelah Selatan berbatasan dengan Kec. Mandau \& Kabupaten Siak.

- Sebelah Barat berbatasan dengan Kabupaten Siak

- Sebelah Timur berbatasan dengan Kec. Merbau \& Kec. Bengkalis

\subsection{Pemilihan Lokasi Penelitian}

Kecamatan Siak Kecil merupakan wilayah yang akan dikembangkan sebagai sentra produksi makanan. Lebih tepatnya wilayah ini akan dibangun sebagai pusat pertanian dan peternakan, yang diharapkan dapat mensuplai kebutuhan pangan di wilayah Bengkalis. $\mathrm{Di}$ wilayah kecamatan ini juga telah direncanakan untuk membangun lahan pertanian padi seluas $1500 \mathrm{Ha}$.

Untuk menunjang pembangunan lahan pertanian ini, pemda kabupaten juga telah membangun sistem pengairan irigasi olah sawah KSP Sepotong, melalui proyek yang telah dilaksanakan pada tahun 2008 ini. Disamping itu di wilayah sepotong ini juga telah dibangun sarana pengolahan hasil panen padi, yaitu dengan mendirikan RPC (Rice Procesing Centre) dengan kapasitas 6 ton per jam. Di wilayah Siak Kecil ini juga telah didirikan satu pusat penggemukkan sapi dengan berbagai fasilitasnya 1).
Berdasarkan perencanaan, wilayah Siak Kecil yang akan dijadikan pusat produksi pangan dan telah dibangunnya berbagai sarananya tersebut, maka sudah tepat kalau penelitian ini dilakukan di wilayah Kec. Siak Kecil. Pelaksanaan pemilihan lokasi dipusatkan di sepanjang aliran sungai Siak Kecil dan sepanjang saluran kanal Sungai Siak Kecil, lebih tepatnya dipusatkan di Desa Langkat.

Desa Langkat berada di sebelah Timur dari Desa Sepotong. Desa ini berada di kawasan pasang surut air laut. Tanahnya pada bagian bawahnya bergambut dan mempunyai kadar besi dan mangan yang tinggi, sehingga sebagian masyarakat desa tidak menggunakan air tanah untuk memenuhi kebutuhan makan dan minumnya. Kedalaman sumur yang lebih dari 7,5 meter umumnya sudah berasa payau.

Untuk memenuhl kebutuhan air bersih sebagian masyarakat desa menggunakan air hujan, sedangkan untuk mandi dan cuci menggunakan air tanah dengan cara membuat sumur gali. Sumur gali rata-rata mempunyai kedalaman 5 meter. Gambar 3. menunjukkan kegiatan survai penentuan lokasi penelitian, sedangkan gambar 4 . menunjukkan foto lokasi yang direncanakan untuk penelitian.

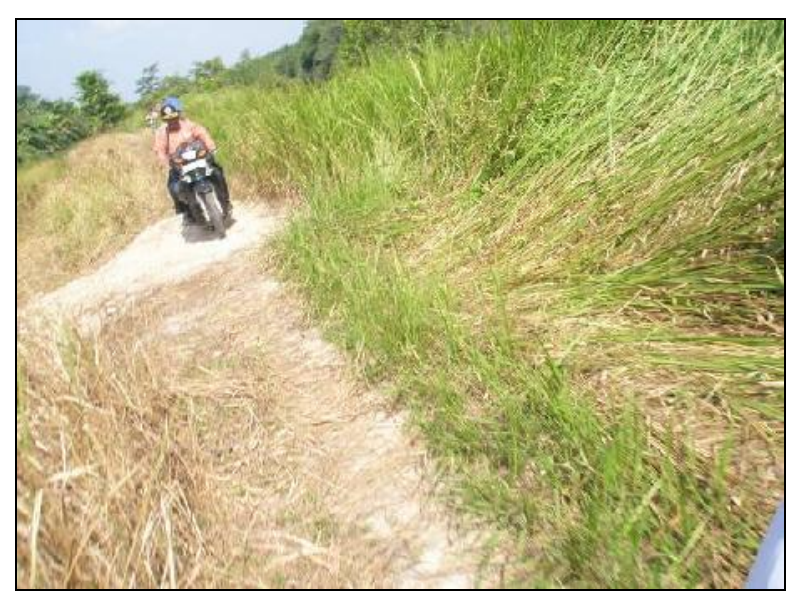

Gambar 3. Kegiatan Survai Lapangan Untuk Penentuan Lokasi Penelitian

Untuk keperluan pertanian Masyarakat Desa Langkat menggunakan Air sungai dari Anak Sungai Siak. Keasaman air sungai ini ratarata $\pm \mathrm{pH}=4,0$. Karena dipengaruhi oleh pasang surut air laut, maka kadang-kadang air yang dapat digunakan hanya pada saat air sungai surut, sedangkan pada saat pasang, air sungai mempunyai kadar garam yang sangat tinggi (TDS > 15.000 ppm). Gambar 5. menunjukkan foto lokasi sungai (sumber air untuk penelitian). 


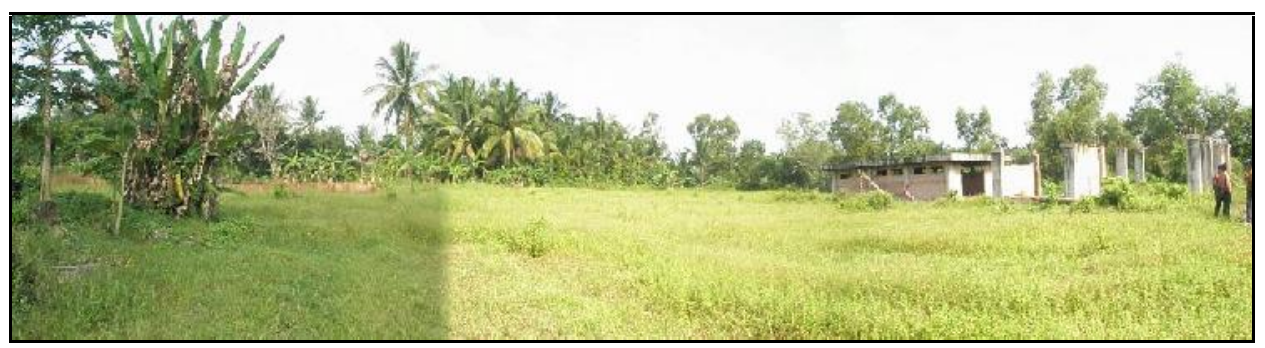

Gambar 4. Calon Lokasi Penelitian Di Tepi Canal Sungai Siak Kecil, Desa Langkat

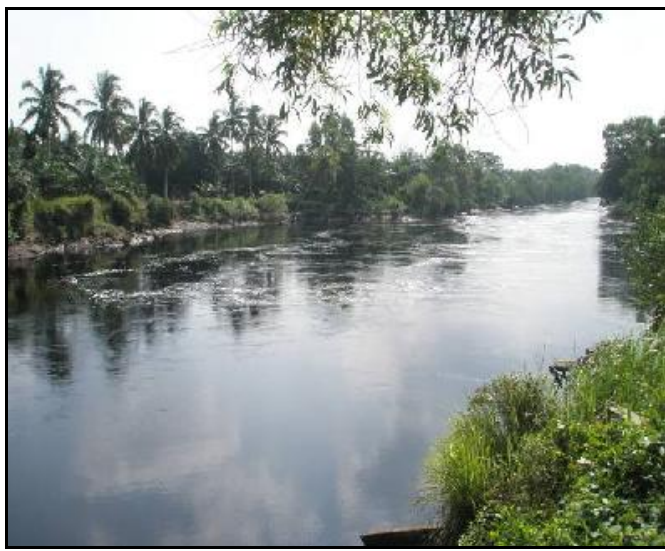

Gambar 5. Sungai Sumber Air Yang Akan Dimanfaatkan Untuk Penelitian

\subsection{Uji Lapangan}

Untuk menentukan teknologi yang akan digunakan dan perancangan bangunan unit pengolahan air ini, maka telah dilakukan pemeriksaan di lapangan kondisi air sungai dan penelitian tahap awal terhadap kondisi air sungai dan lokasi penanaman padi. Penelitian awal dilakukan dengan pengambilan sampel air sungai dan perlakuan awal terhadap air untuk menaikkan $\mathrm{pH}$. Sampel air juga dibawa ke laboratorium untuk dianalisa kualitas air sungai tersebut. Gambar 6 dan 7 menunjukkan kegiatan pengambilan sampel dan uji analisa air di lapangan secara langsung.

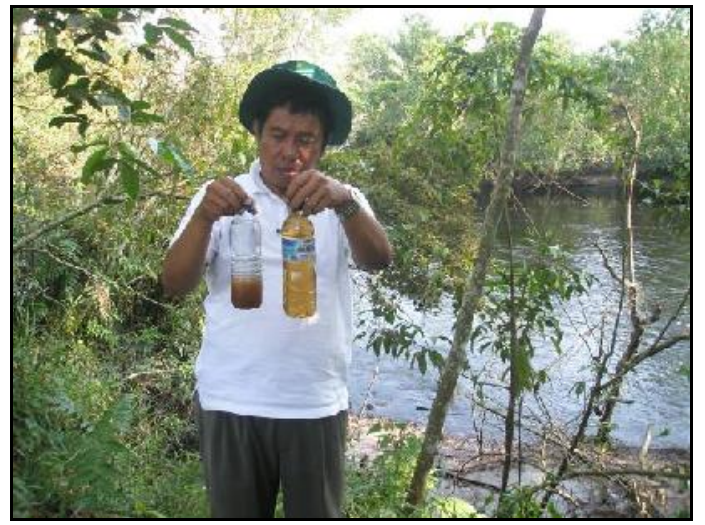

Gambar 6. Pengambilan Sampel Air Sungai Untuk Dianalisa

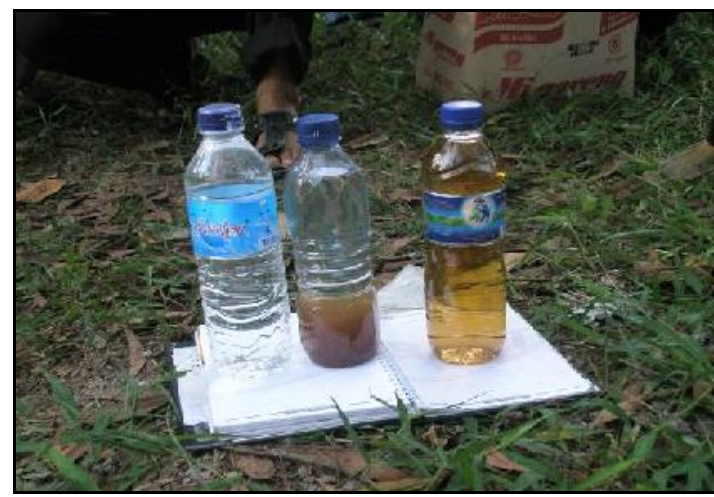

Gambar 7. Contoh Air Sungai Yang Dicoba Untuk Proses Penjernihan

Adapun karakteristik kondisi air sungai pasang surut ialah sebagai berikut ${ }^{1)}$ :

- Pada saat air sungai mulai pasang, maka arus air sungai dari laut menuju daratan. Arah arus sungai pasang ini berlangsung selama \pm 2 jam .

- Setelah itu kondisi pasang berlangsung selama 2 jam. Pada kondisi ini air sungai seolah tidak bergerak (seperti diam tidak ada arus).

- Kemudian setelah itu air sungai mulai surut. Proses surut juga berlangsung selama 2 jam.

- Sehingga pengaruh pasang dimana kandungan garamnya tinggi adalah selama 6 jam.

- Pada saat air sungai surut barulah dapat digunakan untuk keperluan air irigasi.

\subsection{Analisa Laboratorium}

Analisa laboratorium dilakukan terhadap kualitas air sungai yang akan diolah untuk keperluan pertanian dan terhadap kualitas tanah untuk lokasi yang direncanakan penanaman padi. Hasil analisa selengkapnya dapat dilihat seperti pada Tabel 1. 
Tabel1. Hasil Analisa Kualitas Air Sungai Siak (Pada saat surut)

\begin{tabular}{|c|c|c|c|c|c|}
\hline NO & PARAMETER & SATUAN & BAKU MUTU & HASIL & METODE \\
\hline$A$ & FISIKA & & & & \\
\hline 1. & Suhu (lab) & $0 c$ & Udara $\pm 5^{\circ} \mathrm{C}$. & 26,0 & SNI 06-6989,23-2005 \\
\hline 2. & Zat padat terlarut (TDS) & $\mathrm{mg} / \mathrm{L}$ & 2000 & 23 & SNI 06-6989,27-2005 \\
\hline 3. & Zat tersuspensi (TSS) & $\mathrm{mg} / \mathrm{L}$ & 400 & 9 & SNI 06-6989,3-2004 \\
\hline B & KIMIA & & & & \\
\hline 1. & $\mathrm{pH}\left(26^{\circ} \mathrm{C}\right)$ & - & $5-9$ & 4,0 & SNI 06-6989,11-2004 \\
\hline 2. & Air Raksa $(\mathrm{Hg})$ & $\mathrm{mg} / \mathrm{L}$ & 0,005 & $<0,0005$ & SNI 19-6964,2-2003 \\
\hline 3. & Arsen (AS) & $\mathrm{mg} / \mathrm{L}$ & 1 & $<0,005$ & Std. Method (Ed 21) 3500 As \\
\hline 4. & Boron (B) & $\mathrm{mg} / \mathrm{L}$ & 1 & $<0,01$ & SNI 06-2481-1991 \\
\hline 5. & Oksigen terlarut (DO) & $\mathrm{mg} / \mathrm{L}$ & 0 & - & SNI 06-6869.14-2004 \\
\hline 6. & Pospat total $\left(\mathrm{PO}_{4}\right)$ & $\mathrm{mg} / \mathrm{L}$ & 5 & $<0,01$ & SNI 06-2483-1991 \\
\hline 7. & Kadmium $(\mathrm{Cd})$ & $\mathrm{mg} / \mathrm{L}$ & 0,01 & $<0,003$ & SNI 06-6989,16-2004**) \\
\hline 8. & Khromium VI $\left(\mathrm{Cr}^{6+}\right)$ & $\mathrm{mg} / \mathrm{L}$ & 0,01 & $<0,01$ & Std. Method (Ed 21) $3500 \mathrm{Cr} B$ \\
\hline 9. & Kobalt (Co) & $\mathrm{mg} / \mathrm{L}$ & 0,2 & $<0,02$ & SNI 06-2471-1991 \\
\hline 10. & Nitrat $\left(\mathrm{NO}_{3}-\mathrm{N}\right)$ & $\mathrm{mg} / \mathrm{L}$ & 20,0 & 0,6 & Std. Method (Ed 21) 4500-E \\
\hline 11. & Selenium (Se) & $\mathrm{mg} / \mathrm{L}$ & 0,05 & $<0,002$ & Std. Method (Ed 21) 3500-Se \\
\hline 12. & Seng (Zn) & $\mathrm{mg} / \mathrm{L}$ & 2 & $<0,002$ & SNI 06-6989,7-2004**) \\
\hline 13. & Tembaga (Cu) & $\mathrm{mg} / \mathrm{L}$ & 0,2 & $<0,02$ & 18-5A/IK-Cu \\
\hline 14. & Timbal $(\mathrm{Pb})$ & $\mathrm{mg} / \mathrm{L}$ & 0,1 & $<0,01$ & SNI 06-6989,8-2004**) \\
\hline 15. & $\mathrm{BOD}_{5}$ & $\mathrm{mg} / \mathrm{L}$ & 12 & 15 & SNI 06-2503-1991 \\
\hline 16. & COD ( Bicromat) & $\mathrm{mg} / \mathrm{L}$ & 100 & 123 & SNI 06-6989,15-2004 \\
\hline
\end{tabular}

Sumber : "Laporan Proyek Peningkatan Kualitas Air Sungai Untuk Irigasi” BPPT - 2008 1).

Keterangan ${ }^{2)}$ :

$\left.{ }^{*}\right) \quad=$ AIR PERMUKAAN, Peraturan Pemerintah No. 82 Tahun 2001 Kelas IV : Air yang peruntukkannya dapat digunakan untuk mengairi pertanaman dan atau peruntukkan lain yang mensyaratkan mutu air yang sama dengan kegunaan tersebut.

${ }^{* *}$ ) = Logam merupakan logam terlarut.

$<\quad=$ Lebih kecil

\subsection{Tahap Disain dan Konstruksi}

Berdasarkan analisa laboratorium terhadap kualitas air sungai yang akan digunakan sebagai sumber air irigasi, permasalahan utama adalah kualitas nilai $\mathrm{pH}$ air yang rendah. Untuk mengatasi hal ini, maka proses pengolahan yang diterapkan cukup hanya dengan menaikkan $\mathrm{pH}$ air saja atau dikenal dengan proses netralisasi. Air sungai yang ada di lokasi penelitian pada umumnya dalam kondisi tawar, tetapi banyak mengandung zat organik sehingga warnanya coklat, airnya bersifat masam, dengan $\mathrm{pH}$ antara $3 \mathrm{~s} / \mathrm{d} 5$, tergantung musimnya. Untuk keperluan pengembangan pertanian padi di Kabupaten Bengkalis diperlukan air yang tidak masam.
Untuk menunjang sistem irigasi pertanian seluas $1.500 \mathrm{Ha}$ yang direncanakan oleh Pemerintah Kabupaten Bengkalis rencananya akan diambilkan dari air sungai yang ada disekitarnya. Adanya pengaruh pasang surut yang jauh masuk ke daratan juga diperkirakan dapat menghambat pemanfaatan air sungai tersebut, terutama pada musim kemarau panjang, namun karena pasang surut waktunya dapat diprediksi, maka secara teknis masih bisa disiasati.

Air sungai yang masam memerlukan perlakuan sebelum dialirkan ke persawahan. Usaha yang akan dilakukan adalah dengan menaikkan $\mathrm{pH}$ air sampai kepada nilai yang 
sesuai untuk varitas padi yang akan ditanam. Perhitungan dosis dan jenis proses yang akan dipakai perlu dilakukan uji coba di lapangan. Untuk itu diperlukan lahan yang akan digunakan untuk system pengolahan air untuk untuk menaikkan $\mathrm{pH}$ nya agar sesuai dengan kebutuhan untuk air pertanian.

Selama ini, perlakuan air sungai agar dapat digunakan untuk memenuhi kebutuhan air pertanian yang dilakukan oleh masyarakat setempat adalah dengan menaburkan kapur/dolomit secara langsung ke lokasi lahan pertanian sebelum dialiri air. Gambar 8 menunjukkan salah satu jelis kapur dolomit yang sering dipakai petani di Bengkalis untuk menaikkan $\mathrm{pH}$ air untuk memenuhi kebutuhan irigasi pertanian padi.

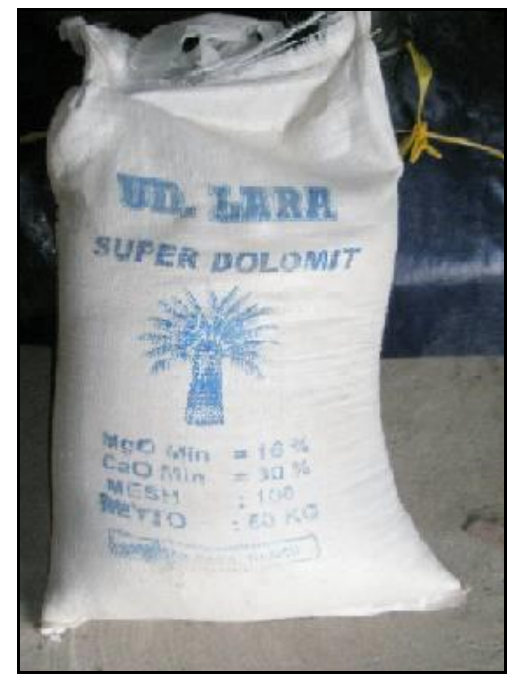

Gambar 8. Salah Satu Jenis Kapur Dolomit Yang Dipakai Masyarakat

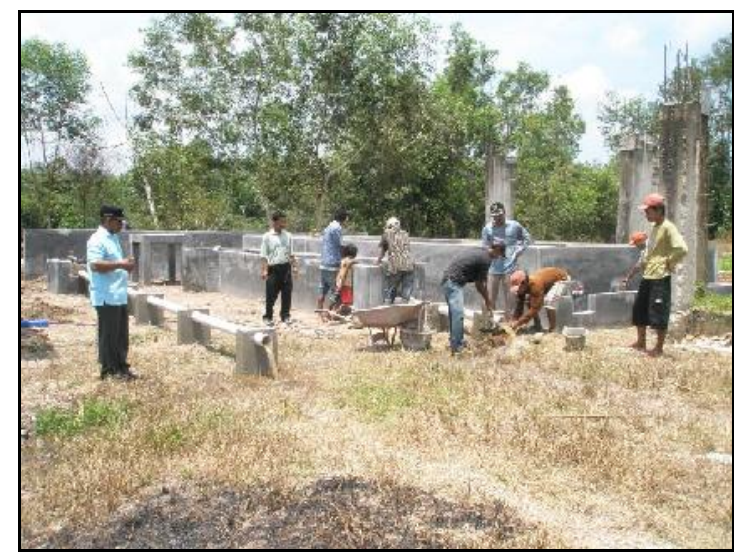

Gambar 9. Kegiatan Pelaksanaan Konstruksi Fisik Unit Penelitian

Selain dengan menaburkan kapur ke lahan pertanian, upaya untuk menaikkan $\mathrm{pH}$ air juga dapat dilakukan dengan menambahkan larutan kapur ke dalam air yang masam dibarengi dengan pengadukan yang biasa disebut proses penaikan $\mathrm{pH}$ secara aktif. Cara ini dapat menaikkan $\mathrm{pH}$ air secara langsung, karena larutan kapur yang pekat dapat langsung terlarut ke dalam air secara homogen. Jika melakukan cara ini maka $\mathrm{pH}$ air olahan harus dikontrol secara rutin, sebab jika air olahan tidak dikontrol seraca rutin maka kemungkinan terjadinya kesalahan $\mathrm{pH}$ sangat besar sekali. Sedikit perbedaan konsentrasi larutan kapur dalam air akan besar sekali terhadap perubahan $\mathrm{pH}$.

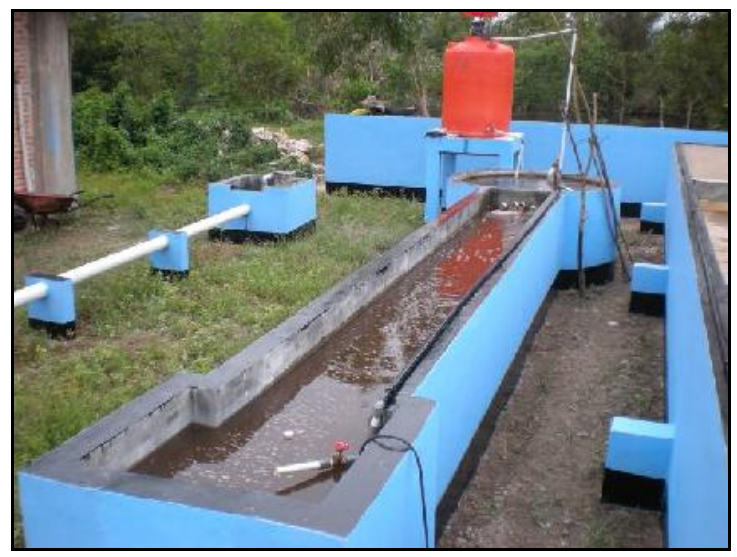

Gambar 10. Foto Unit Pengolahan Air Pada Saat Dioperasikan

Cara lain untuk menaikkan $\mathrm{pH}$ air dapat dilakukan dengan melewatkan air asam melalui canal/ saluran yang bagian bawahnya telah ditata batu-batu kapur. Sistem ini dikenal dengan pasif treatment. Jika dengan menggunakan sistem ini, maka akan terjadi proses pelarutan kapur ke dalam air, sehingga air yang bersifat asam $\mathrm{pH}$ nya akan naik. Jika menggunakan sistem ini, maka kita akan sedikit kesulitan dalam melakukan kontrol terhadap $\mathrm{pH}$ air yang diinginkan, sebab sifat atau kualitas kapur yang digunakan serta waktu kontak antara air dengan kapur akan sangat mempengaruhi $\mathrm{pH}$ akhir dari air tersebut. Kelemahan lain sistem ini adalah kualitas kapur yang semakin lama akan semakin berkurang sifat kelarutannya sehingga akan mempengaruhi $\mathrm{pH}$ akhir yang dihasilkan. Gambar 11 menunjukkan cara menaikkan pH air dengan sistem aktif treatment dan pasif treatment.

Setelah selesainya disain teknis proses selesai dilakukan dan hasil disain berupa gambar teknis secara detail serta keterangan proses diselesaikan, maka tahap konstruksi fisik dapat dilakukan. Konstruksi fisik di lapangan dilakukan oleh tenaga yang sudah berpengalaman serta diawasi langsung oleh tim peneliti dan perancang disain dari BPPT maupun dari Kementerian Ristek secara langsung. 


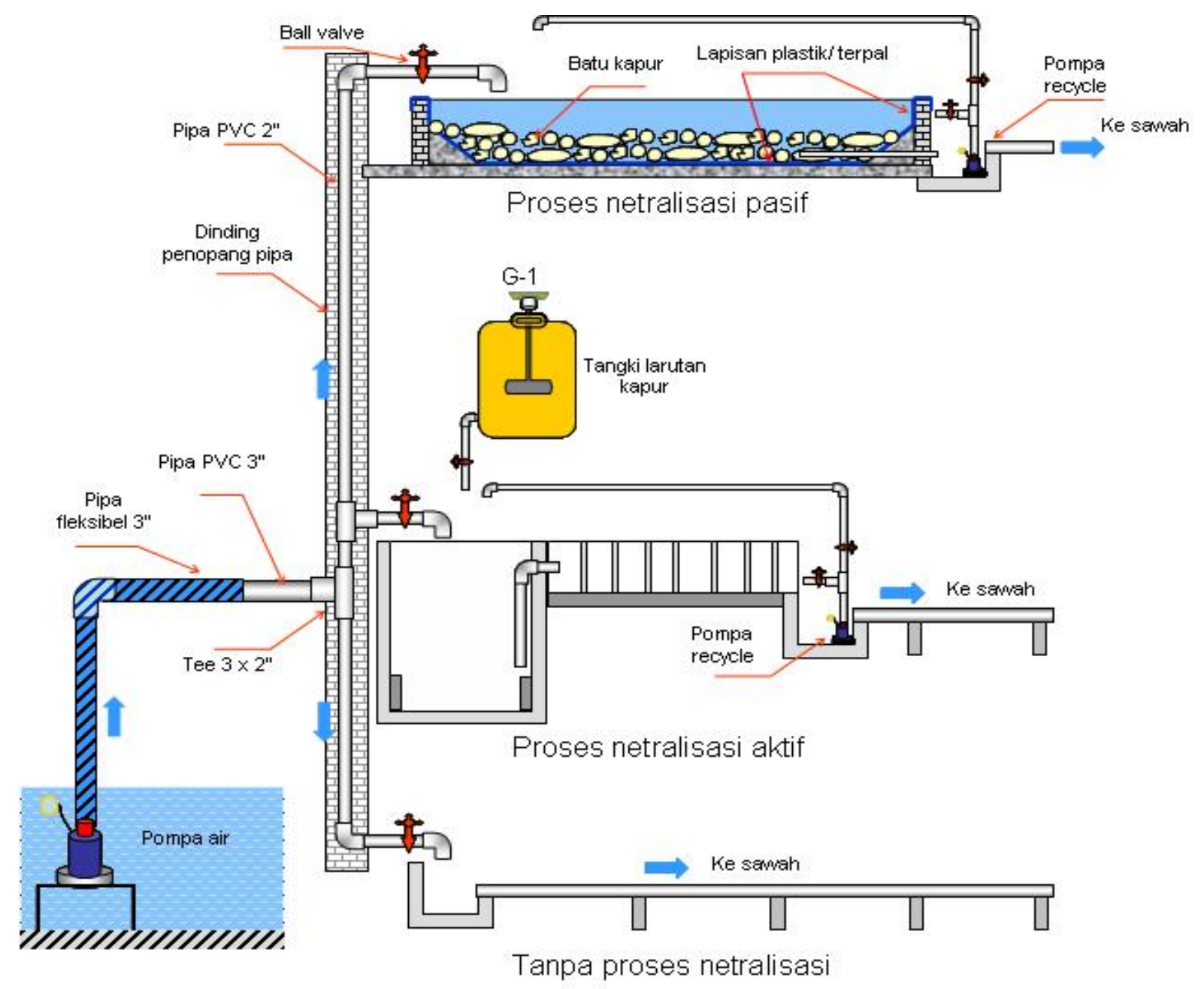

Gambar 11. Sistem Penaikan pH Air Asam Dengan Pasif Treatment dan Aktif Treatment ${ }^{1}$.

\subsection{Hasil Pengamatan}

Operasional unit pengolahan air ini dilakukan oleh seorang operator yang telah dilatih dan memahami sistem secara detail. Disamping diberikan pelatihan khusus, dalam pelaksanaan kerjanya operator juga dilengkapi dengan buku panduan operasioanal sistem kerja unit pengolahan dan buku catatan monitoring hasil kerja. Dalam pelaksanaan operasional sistem juga dipantau langsung oleh tim peneliti dari UPTD Pertanian dan Peternakan setempat.

Berikut adalah panduan sistem operasi unit pengolahan air :

\section{A. Pemeriksaan Kondisi Peralatan :}

1. Pemeriksaan kondisi peralatan dan mesin.

2. Pemeriksaan isi BBM dan oli di generator.

3. Pastikan semua sambungan kabel dalam keadaan yang aman.
4. Pemeriksaan kondisi kran air di aktif treatment dan kran yang langsung dalam posisi terbuka.

\section{B. Menyiapkan Larutan Kapur :}

1. Timbang kapur sebanyak 500 gram.

2. Larutkan kapur ke dalam air dengan menggunakan ember.

3. Isi tangki larutan kapur dengan air.

4. Masukkan larutan kapur dalam ember ke dalam tangki larutan kapur.

5. penuhi tangki larutan kapur hinggan penuh (500 It).

\section{Mengoperasikan Sistem :}

1. Hidupkan generator.

2. Atur perbandingan aliran air dari pompa ke dalam bak aktif treatment dan bak langsung dengan perbandingan $1: 2$. 
3. Buka kran tangki larutan kapur, sehingga larutan dapat mengalir masuk ke bak aktif treatment dengan kecepatan 2 liter per menit.

4. Setelah semua posisi kran tersetting, maka tunggu sekitar 10 - 15 menit.

5. Ukur pH air olahan dari aktif treatment.

6. Jika $\mathrm{pH}$ air < dari 6,5 , maka tambah sedikit bukaan kran larutan kapur, kemudian 10 - 15 menit kemudian cek kembali $\mathrm{pH}$ outlet air olahannya.

7. Jika $\mathrm{pH}$ air > dari 7,5, maka kurangi /tutup sedikit bukaan kran larutan kapur, kemudian 10 - 15 menit kemudian cek kembali pH outlet air olahannya.

Perhitungan Kebutuhan Kapur dan Hasil Operasional Sistem :

$\begin{array}{ll}\text { Konsentrasi larutan kapur } & =500 \mathrm{~g} / 500 \mathrm{It} \\ & =1.000 \mathrm{ppm} \\ \text { Kapasitas pompa } & =500 \mathrm{It} / \text { menit. }\end{array}$

Perbandingan debit ke aktif treatment : langsung $=1: 2$

Debit air ke unit aktif treatmen

$=(1 / 3) \times 500$ lt $/$ menit

$=167 \mathrm{It} / \mathrm{mnt}$

Debit larutan kapur $\quad=2 \mathrm{lt} / \mathrm{mnt}$.

Rumus $\mathrm{Q}_{1} \times \mathrm{C}_{1}=\mathrm{Q}_{2} \times \mathrm{C}_{2}$

2 It $/ \mathrm{mnt}$ x $1.000 \mathrm{ppm}=167 \mathrm{lt} / \mathrm{mnt} . \times \mathrm{C}_{2}$

$\mathrm{C}_{2}=11,97 \mathrm{ppm}$.

Data yang menunjukkan hasil pengoperasian peralatan untuk meningkatkan kualitas air baku dapat dilihat pada lampiran tabel 2.

\section{KESIMPULAN DAN REKOMENDASI}

\subsection{Kesimpulan}

- Air Sungai dan Anak Sungai /Kanal Siak Kecil bersifat asam, sehingga beresiko tinggi jika digunakan untuk irigási pertanian.

- Air yang bersifat asam ini dapat diolah dengan menaikkan $\mathrm{pH}$ air jika akan digunakan untuk irrigási pertanian.

- $\quad$ Cara penaikkan pH yang paling mudah serta mudah dalam pengontrolan adalah dengan proses aktif (membubuhkan larutan kapur ke dalam air).

- Larutan kapur disamping dapat menaikkan $\mathrm{pH}$ air juga dapat memperbaiki struktur tanah setempat untuk lahan pertanian.
- Sumber air yang berlimpah di wilayah Siak ini dapat dimanfaatkan untuk keperluan irigasi dengan terlebih dahulu dilakukan pengolahan secara sederhana.

\subsection{Rekomendasi}

- Lokasi percobaan ini berada di atas tanah milik Pemerintah Daerah Bengkalis seluas 1 Ha. Konstruksi bangunan yang telah dibuat dapat digunakan lagi untuk penelitianpenelitian terhadap budidaya tanaman pertanian lainnya. Sehingga lokasi ini dapat direkomendasikan untuk dijadikan sebagai laboratorium pertanian milik Pemda Kabupaten Bengkalis.

- Teknologi pengolahan air sungai yang telah dibuat pada penelitian ini akan dapat diterapkan untuk memenuhi kebutuhan air irigasi sistem pertanian padi seluas $1.500 \mathrm{Ha}$ di wilayah Kec. Siak Kecil, yang dibangun oleh Pemerintah Daerah Kabupaten Bengkalis.

\section{DAFTAR PUSTAKA}

1. Pusat Teknologi Lingkungan, Laporan Proyek Peningkatan Kualitas Air Sungai Untuk Irigasi Persawahan Di Kabupaten Bengkalis, Riau, PTL - BPPT, 2008.

2. Peraturan Pemerintah No. 82 Tahun 2001 Tentang Pengelolaan Kualitas Air dan Pengendalian Pencemaran Air, Lampiran Kelas IV : Air yang peruntukkannya dapat digunakan untuk mengairi pertanaman dan atau peruntukkan lain yang mensyaratkan mutu air yang sama dengan kegunaan tersebut.

3. Pemerintah Daerah Bengkalis, Bengkalis Dalam Angka 2005.

4. Techobanoglouus, George \& Schroeder, D.Edward, Water Quality, Addison-Wesley Publishing Company, United States of America, 1987.

5. Hammer, Mark J., Water and Wastewater Technology, John Wiley \& Sons, Inc., 1975. 


\section{LAMPIRAN}

Tabel 2. Data Hasil Operasional Peningkatan Kualitas Air

\begin{tabular}{|l|l|c|c|c|c|c|c|}
\hline \multirow{2}{*}{ No } & \multirow{2}{*}{ Hari/ tanggal } & \multirow{2}{*}{ Parameter } & \multicolumn{3}{|c|}{ Unit Aktif Treatmen } & \multicolumn{2}{|c|}{$\begin{array}{c}\text { Unit Tanpa } \\
\text { Pengolahan }\end{array}$} \\
\cline { 3 - 8 } & & $\mathrm{pH}$ & 4,5 & 11,97 & 6,7 & 4,5 & 4,5 \\
\hline 1 & $\begin{array}{l}\text { Selasa/ } \\
02 / 12 / 08\end{array}$ & $\mathrm{pH}$ & 4,5 & 11,97 & 6,7 & 4,5 & 4,5 \\
\hline 2 & $\begin{array}{l}\text { Selasa/ } \\
\text { Kapur }(\mathbf{p p m})\end{array}$ & Outlet & Inlet & Outlet \\
\hline 3 & $\begin{array}{l}\text { Rabo/ } \\
03 / 12 / 08\end{array}$ & $\mathrm{pH}$ & 4,5 & 11,97 & 6,6 & 4,5 & 4,5 \\
\hline 4 & $\begin{array}{l}\text { Rabo/ } \\
03 / 12 / 08\end{array}$ & $\mathrm{pH}$ & 4,5 & 11,97 & 6,6 & 4,5 & 4,5 \\
\hline 5 & $\begin{array}{l}\text { Kamis/ } \\
04 / 12 / 08\end{array}$ & $\mathrm{pH}$ & 4,0 & 12,20 & 6,7 & 4,0 & 4,0 \\
\hline 6 & $\begin{array}{l}\text { Kamis/ } \\
04 / 12 / 08\end{array}$ & $\mathrm{pH}$ & 4,0 & 12,20 & 6,6 & 4,0 & 4,0 \\
\hline 7 & $\begin{array}{l}\text { Jumat/ } \\
05 / 12 / 08\end{array}$ & $\mathrm{pH}$ & 4,5 & 11,97 & 6,6 & 4,5 & 4,5 \\
\hline
\end{tabular}

Sumber : "Laporan Proyek Peningkatan Kualitas Air Sungai Untuk Irigasi” BPPT - 2008 1) 


\begin{abstract}
Abstrak
Kabupaten Bengkalis mempunyai penduduk 690.366 jiwa yang tersebar dalam wilayah seluas $11.481,77 \mathrm{Km}^{2}$.Potensi sumber daya alam diwilayah tersebut cukup besar, sehingga Pemerintah Daerah mempunyai komitmen yang tinggi untuk memenuhi kebutuhan pangan lokal, bahkan regional . Guna melaksanakan tujuan tersebut, akan dibangun sistem irigasi untuk mengairi 1500 ha lahan persawahan yang kekurangan air dimusim kemarau. Namun ada beberapa kendala yang dialami antara lain adalah : sungai untuk sumber air irigasi terletak didekat pantai, sehingga dipengaruhi oleh pasang surut air laut. Disamping itu airnya bergambut sehingga mengandung kadar organik yang tinggi dan bersifat masam. Untuk menanggulangi hal tersebut perlu dilakukan pengolahan air sungai untuk irigasi, sehingga kualitasnya memenuhi syarat untuk pertanian. Sedangkan kondisi pasang surut dapat diatasi dengan mengatur waktu pemompaan. Dari hasil penelitian di laboratorium menunjukkan bahwa $\mathrm{pH}$ air sungai = 4 sedangkan baku mutu air sungai untuk persawahan yang sesuai adalah $5-9 \mathrm{mg} / \mathrm{l}$. Oleh karena itu diperlukan pengolahan air untuk menaikkan $\mathrm{pH}$ agar sesuai dengan baku mutu air untuk pertanian.Penelitian dilakukan di desa Langkat, kecamatan Siak Kecil. Meliputi penelitian Laboratorium, disain pembuatan alat untuk menaikkan $\mathrm{pH}$ air sungai irigasi, pembangunan alat, sampai dengan uji coba dan monitoring.
\end{abstract}

\begin{abstract}
Bengkalis district has a population of 690,366 people spread in the area of 11,481.77 $\mathrm{Km}^{2}$. Natural resources potencial in this area is quite large, so that local Government has a high commitment to meet the demand of local food, and even regional. To implement this goal, local government will build irrigation systems to irrigate 1,500 ha of rice field land which decrease of water in dry season. However, there are some constraints experienced are : the river for irrigation water source is located near the beach, so it is influenced by tidal sea water. Besides, the peat moss water contains a high organic matter and acid. To solve this problem, we need to treat the river water for irrigation, so that its quality meets the requirement for agriculture. While tidal conditions can be set with the pumping time. From the results of the research in the laboratory showed that the river water $\mathrm{pH}=4$ while the river water quality standard for the rice field is the appropriate 5 - $9 \mathrm{mg} / \mathrm{l}$. Therefore, the required water treatment to raise $\mathrm{pH}$ to comply with the standard quality of water for agriculture. Research conducted in the village Langkat, district Siak Kecil. This activity includes laboratory research, design creation tool to increase $\mathrm{pH}$ river water irrigation, tools development, up to the trials and monitoring.
\end{abstract}

